\title{
Child and adolescent psychiatry in Europe
}

\author{
Tuula Tamminen
}

Published online: 30 September 2011

(C) Springer-Verlag 2011

This issue of European Child and Adolescent Psychiatry is historical. The publisher of the Journal and the European Society for Child and Adolescent Psychiatry, ESCAP have now signed a landmark agreement on a new cooperation. With this agreement, the Journal and ESCAP re-establish their close relationship, and from now on the Journal is once more the official journal of ESCAP.

The earliest roots of European child psychiatry can be traced back to the 1800s. In the early twentieth century and until the Second World War (1939-1945), child psychiatry developed separately in various European countries. In 1954, some Swiss, French, and German academic child psychiatrists came together for an informal meeting in Switzerland. This started off a series of further meetings with larger numbers of European participants. Finally, in 1960, the European Society of Child Psychiatrists was formed in Paris, where its first official meeting was held. The ESCAP in its earliest form came into being and one cornerstone for European professional collaboration was laid.

The other basic foundation for communication between European psychiatrists working with children and adolescents came about also in 1954, when the very first child psychiatric journal, the Zeitschrift für Kinderpsychiatrie in Switzerland, was transformed into Acta Paedopsychiatrica with contributions in German, French, and English. In 1991, after Acta Paedopsychiatrica had ceased as a journal, a new journal was launched under the title "European

T. Tamminen $(\bowtie)$

University and University Hospital of Tampere,

Child Psychiatry Medical School,

University of Tampere, 33014 Tampere, Finland

e-mail: tuula.tamminen@pp.fimnet.fi
Child and Adolescent Psychiatry". This started to be the official organ of ESCAP.

In 20 years, both ESCAP and the Journal have grown and developed along with multidimensional progress in the field of child and adolescent psychiatry. Vast strides forward have been made in all levels of European collaboration. In today's Europe, both national and international networks are a necessity and global integration irreversible. Again, it is crucial that ESCAP and the Journal join forces to increase the knowledge and expertise on child and adolescent psychiatry and promote mental health based on European values and the rich European cultural context.

This year in June, during the 14th official ESCAP Congress in Helsinki, the General Assembly of ESCAP approved the new Bylaws for the Society. This major advance modernizes the structure of the over 50-year-old association. ESCAP is still the umbrella organization of 32 national societies of child and adolescent psychiatry, but now it also has three subdivisions.

The Academic Division of ESCAP will act as a forum for exchange of scientific research and promote education and training, especially research training in the field of child and adolescent psychiatry and mental health. In Europe, funding for basic research has significantly increased during recent years, and in 2009 the European Commission launched a strategic view of the European Research Area, called Preparing Europe for a New Renaissance. Translational research combining studies from cells to patients will be followed by even more comprehensive transformative research focusing on the implementation of research results from basic sciences into patient care, services, and public and private innovations. Mental health challenges and early interventions will be among the research areas of growing importance. 
The role of the Clinical Division of ESCAP is to enhance the quality of professional work and activities in child and adolescent psychiatry and the standing of the profession. On the one hand, Clinical Centers of Excellence where research results are implemented and evidence-based care valued are needed at national level, also their networks across Europe. On the other hand, promoting mental health plus developing and supporting primary level services will be the best way to tackle the rapidly growing need for interventions.

The Policy Division of ESCAP will promote national health policies, raise public awareness and foster public advocacy related to the mental health of children, adolescents, and their families. Also, it is essential to raise the standing and authority of ESCAP in Europe and in the European Union in order to promote children's rights to adequate care when needed.
One of the main aims of the new structure of ESCAP is to offer child and adolescent psychiatrists more and more opportunities to be active and involved in the actions of ESCAP. The philosophy of the cooperation agreement between ESCAP and the Journal pursues the joint aim to enhance the visibility of ESCAP in the field of European and international child and adolescent psychiatry. Also, the goal of the agreement is to fulfill ESCAP's mandate to ensure the continuing education of its members. In order to succeed in these efforts, it is important that the increasing number of child and adolescent psychiatrists find the Journal useful, interesting, and stimulating.

Developing the Journal and ESCAP are now critical steps, so that they can serve effectively as tools for all child and adolescent psychiatrists in Europe faced with the challenges posed by the third millennium to human mental development, capacity, and health. 